\title{
The Informal Tourism Economic Model of the Ethnic Minority Regionsin Southwest China
}

\author{
Yusu Qin (Corresponding author) \\ School of Commerce and Social Studies \\ Chongqing University of Science and Technology, China \\ E-mail: qyusu@yahoo.com
}

Yang Qi

School of Civil Engineering and Architecture

Chongqing University of Science and Technology, China

$\&$

Graduate Institute of Building and Planning, National Taiwan University, China

\author{
Received: September 19, 2017 Accepted: March 29, $2018 \quad$ Published: April 16, 2018 \\ doi:10.5296/jad.v4i1.11887 URL: https://doi.org/10.5296/jad.v4i1.11887
}

\begin{abstract}
Yunnan province located in Southwest China and owns a variety of tourism resource that makes him become one of the most popular tourist resorts. But, due to these ethnic minorities who are directly transferred from the primitive commune economy and feudal lord economy to modern market economy disable to grip the operation essence of the current economy system and the out-comers who are proficient in the market competition crowded out the natives and occupied the resources, the economy of Yunnan separated into two skin which produced the ethnic tensions and obstacles of economic development. Under this circumstance, informal economy plays a non-negligible role. Through a field work in the northeast areas of these regions, we found that a kind of informal tourism economy model that through constituted an informal tourism network which consisted of varieties of travel agencies, local restaurants, hotels and inns to collecting the individual tourists to forming a tour group called Individual Spell Group. This complementary network attracts tourists to buy their tour package in an ultra- low price and inducing them to shopping in some of special shopping spots operated by local ethnic minorities in a way we called 'Soft compulsive shopping'. So, that, the funds be ingeniously transferred to the pocket of local ethnic minorities and then distributing to the other members of this network. In addition, our research found that by artfully utilizing the change of
\end{abstract}


tax levy way, this kind of informal model also help local government to avoiding revenue levied by the state and keep the funds to developing this region. We believe the informal economy not only play an important role in some economic system especially where the modernity absent but also could efficiently solving the social problems, changing political force and, ultimately, effecting the people's thinking.

Keywords: Informal economy, ethnic minority, tourism, Yunnan of China

\section{Introduction}

'Colorful Yunnan, a tourist paradise', as the sloganeer of the tourism of Yunnan Provence represent the plentiful tourism resource of this region where 26 minorities each has its own characteristics that makes these scene of those region varies step by step. These features are become the one of most popular destination of the whole country $\{\mathrm{Zi}, 2013 \# 92\}$. There are three alternative routes for tourists to traveling in Yunnan: The first one, from Tengchong to Ruili, the second one, from Dali to Lijiang, and then to Shangrila. And the third route, tourists could directly fly to Xishangbanna. The tourists who chose the second route would firstly arrive in Lijiang as the central spot for the subsequent travel. As a result, a special tourist group called The Individual Spell Group emerges in this region. This individual spell group is different from the other traditional individual spell group in the past time which is consisted by a few of individual tourists under the organization of a specific travel agency. These tourists of the individual spell group in this region offered by the local inns, restaurants and the travel agencies in different scales in varieties of items which like the special offer, the gift for the shopping or the item contains in the hotel package. And the prices also vary, ranging from 600RMB to free. A specific travel agency will arrange the field trips and sightseeing, and regarding these groups as shopping groups, inducing tourists spending money as possible as them can, and then, distributing the profits to shopping centers and tourists offering agencies(e.g. Small travel agency, inns and restaurants). In this way, these areas forming an economic network constituted by variety kinds of travel agency, inns and hotels, restaurants and vendors of jewelry and traditional native medicine. One of their marketing features is the extremely low price of the tour fee. Usually, most tourists in Lijiang chose independent travel. When they checking into an inn or directly consulting the tour packages in local travel agencies of Lijiang or Dali, they will be offered a lot of preferential terms, just like checking into an inn, $20 \%$ discount of the tow-days trip to Shangri-La will be provided to travelers by this inn or just spending $200 \mathrm{RMB}$, super low-cost, to buying a tow-days trip to Shangri-La, otherwise, giving a tow-days trip to Dali as a present. A couple comes from Liaoning province told us they just paid $280 \mathrm{RMB}$ per head for the trip fee of the tow-days trip to Shangri-La. This kind of low price trip fee is attracting tourists, because for most of them prefer getting services in low cost. And, meanwhile, the tourists, unreasonably, didn't consider the necessary cost of providing these services.

This is an unimaginable low price while thinking about the average transportation cost is 104 RMB per head from Lijiang to Shangri-La, the average hotel accommodation cost is $50 \mathrm{RMB}$ per head and the average catering costs arrange from 30 RMB per head to 90 RBM per head. The all costs for basic needs arrange from $184 \mathrm{RMB}$ to $244 \mathrm{RMB}$ even ignoring the tickets 
costs of each scenic spot not to mention the cost of evening party contains in this package, the $280 \mathrm{RMB}$ cost for the trip is unbelievable low. (Table 1)

Table 1. The Comparison of Trip Fees of The Individual Spell Group and The Cost of Independent Travel

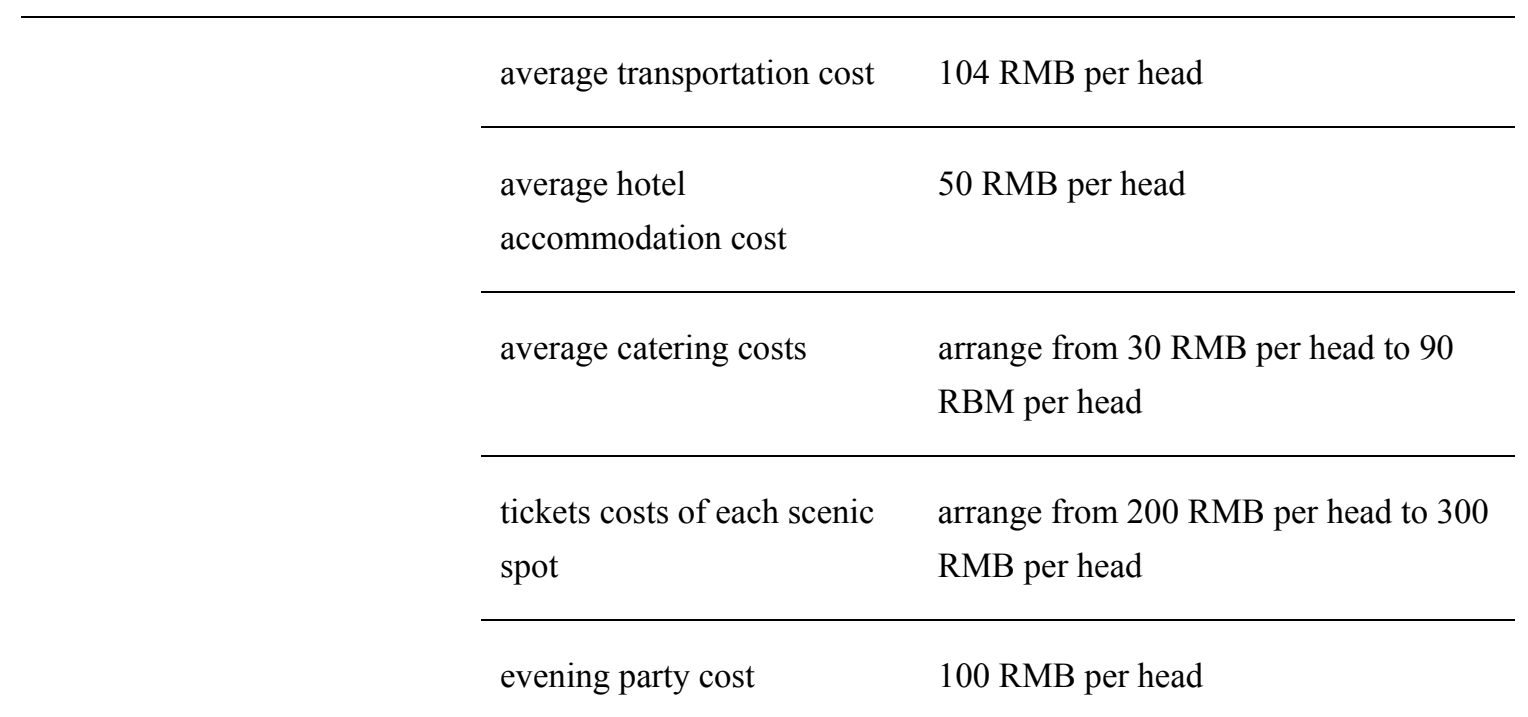

Total Arrange from 200 RMB per Arrange from 484 RMB per head to 644 RMB per head head to free

The data is compiled by the author

This situation is not only happened when travel to Shangri-La, but also to Dali. A couple from Fujian province came to Yunnan a few days ago to accompany their son enrolling into a native university, by the way, walking around to have a vacation. They told us the two-days trip to Dali is a complimentary gift obtain when they checking in an inn in Lijiang. The wife called Ms. Zhang, a high school teacher, said 'When we are hesitating to check, the owner of the inn told us he could send us to play in Dali. We didn't dwell on it, just thinking it's the services of this high-end inn before signing.'

How to get profits from the super low trip fee? The economic network has to facilitating the tourists to expanding their expense on shopping. The method taken by this network, I called, the 'soft compulsive shopping'. There are three shopping spot in the tow-days trip to Shangri-La. They almost sell the alabaster sliver, emerald and the local rare medicinal materials. And practically the same in Dali, travelers required to buying emerald and alabaster sliver.

\subsection{The Soft Compulsive Shopping}

Indeed, it's required. When the guide got on the bus, he will lobby of the tourists to buy their local products by inducing the variety function of these goods. It's not the unique situation 
when you travel, especially in Asia. But, in this region, maybe in Asia, guide will remind you that shopping is a necessary item for this trip. Why you buy some local products? They, the guides in this region, will give you two reasons.

The guide take us to Shangri-La is a Tibetan. He believe the purpose of developing tourism is to developing the local economy, especial bring money from outside to this old land. The method of absorbing the flow of wealth is promoting the tourists' consumption. That's the reason why the trip fees are ridiculous cheap, because it needs tourists to compensate for the lacking by shopping. Similarly, in Dali Bai Autonomous prefecture, a Bai guide told us 'Yunnan is poor, because he lose a half of tax revenue (he means that the tax revenue of tobacco be levied directly be the state, are not included in the local finance). The only way to acquire wealth is to develop tourism. You just think about why trip fee you had paid is so cheap, because the local government have compensate for basic cost of every single trip for attracting the whole country's tourists to travel to Yunnan and spending in Yunnan. You come here, bring your money and spend it in here is contribution to the development of our economy. You have come here, doesn't merely enjoy the scenery and left. Tourism is a price to pay. We entertain you with excellent services, and you need to understand how to return.' And he went on to add. 'Of course, we do not force you to consume. It's illegal. You don't have to consume, but you need to make up the price spread.' At the same time, Shangri-La belong to the Tibetan areas, the guide of this trip is an uninhibited kamba man who puts more pressure on tourists in shopping. He said 'we are not welcome the poor. If you are poor, it's ridiculous to travel, because travel is a luxury. We Tibetans just welcome the one who brings the wealth. Who just pay for a little pity tour fee and want us to offering delicious food and pretty scenery is the most unwelcome person in our mind. For this kind of people who just want to take advantage of our Tibetans, we definitely have lots of ways to punish him.'

Without doubt, he can't do anything if tourists do not shopping at all. Compulsive shopping is illegal in China. This is just his intimidation which manufacturing the tourists' psychological stress. After staying in the shopping spot a few hours, even if you didn't buy anything at all is not having any problem. These tour guides couldn't punish you not only in Dali but also in Shangri-La. That intimidation in bus is just a method to moderately compelling tourists to shopping. The behavior that taking tourists to the shopping spot and compelling them to spending money is absolutely coercive way, but also soft. Different from the usually compulsive shopping, they didn't shut tourists in a shopping spot until them spending money that they could get out. In this region, they just verbal threat, and didn't force on actual behavior. The methods are just typically lobbying and psychological stress. So, I called it 'the soft compulsive shopping'.

\subsection{Traditional Community Economy}

In addition, these shopping spot are more characteristic. Nishi Culture Village located in the side of a road which is the entrance to Pudacuo National Forest Park. It's a secluded hamlet where nobody will believe there is shopping spot selling traditional Tibetan alabaster silverware. The one who inducing the products for us is a Tibetan girl speaking perfect standard Chinese, she told us, she just represent their commune to selling their products which 
is made of by the craftsmen in their commune .These commodities is collected from every single craftsmen, and the commune responsible for selling and distributing the profits to every members in the commune. She said 'Because I have studied in a school, that's why I 'm able to speak standard Chinese and also stay in big city a few years, knowing something about business I was recommended to represent commune to receive you and introducing our products.' And she also mentioned the support from government. 'Nishi Culture Village named by government because they are located in the side of a main road. It's more convenient to escape from poverty. And also because of the good craft of making silverware, local government helps us constitute commune where every member responsible what they are able to do. As a result, I can find that our village is relatively rich.'

Nishi Culture village is not the only this kind of commune in Shangri-La. At a distance of seventeen kilometers away Shangri-La is also the case of another store. This shopping spot is more likely an indoor agricultural goods market, each booth run by one of their members, price was decided by commune. And instead of the formal tax invoices, tourists could only get a receipt named commune as payee.

\section{Informal Economic Model of Tourism}

This tourism model in northern Yunnan is considered commonplace in the global tourism industry, belongs to the informal economy. Based on the institutional rules that go unobserved by a particular economic activity, Feige classified the underground economy into four sub-forms: The illegal economy, the unreported economy, the unrecorded economy and the informal economy. 'The illegal economy encompasses the production and distribution of legally prohibited goods and services; the unreported economy consists of actions that circumvent or evade established fiscal rules as codified in the tax code; the unrecorded economy encompasses activities that circumvent reporting requirements of government statistical agencies; the informal economy comprise economic actions that bypass the costs of, and are excluded from the protection of, laws and administrative rules covering property relationships, torts, financial credit and so on' $\{$ Feige, $1990 \# 58\}$. Obviously, according to the classification above, the economic model of tourism in Yunnan reflected including unreported, unrecorded and informal. First and most important, the super-low price of these products (unreasonable travel packages) apparently not allowing by law. According to the article 35 of Tourism Law of the People's Republic of China, travel agencies are prohibited from organizing tourism activities and luring tourists with unreasonably low prices, or getting illegitimate gains such as rebates by arranging shopping or providing tourism services that requires additional payment $\{C N T A, 2015 \# 227\}$. And then, shunning from the formal purchase model the tax data and profitability not only cannot be recorded comprehensively but also cannot be report in the way it supposed to be. In addition, their economic actions are not in the charge of, at least not in public, the administration. So, this kind of model definitely belongs to the category of underground economy of Feige. But, actually, the four sub-forms above are partly overlapping. So, the most important conceptual distinction is that between informal and illegal activities. Since the specific time and place for production and marketing of his tourism economy model is not illegal, but only the most of their products (unreasonable travel packages) are illegal \{Feige, $1985 \# 228$ \}, we believe it's an informal model but not illegal. 
However, we can notice that the feature of this informal economic model is that it located in an ethnic minority areas. In Yunnan 25 minority substantially directly shift from the slave or feudal lord's society to the modern civilized society. When the modern economic operation model which is based on capital and market push forward into this unprepared society, whether the ethnic minorities can benefit from it, in other words, the life quality of minorities of Yunnan could really promoted or not? Moreover, are there any inextricably link between the informal economic model of tourism above and the economic system of minorities? It's worth to deeply explore.

\section{Method}

Building on the Grounded Theory, this study use participant observation. When Barney Glaser and Anselm Strauss first introduced the grounded theory in 1967, it was be used as an efficient tool to construct theory including in filed like tourism \{Aloudat, $2014 \# 188$ \}. Woodside and his college's work reviews grounded theory studies available in the literature that deepen understanding of leisure travel decision and tourism behavior. They believe studies includes applying the 'long interview method' and 'theoretical sampling' could able to acquiring process data held in the minds of customers. And this kind of analysis would help researchers obtain a rich, deep and nuanced-filled understanding of the causes and consequences of these behaviors by achieving such holistic, case-based views of leisure travel decisions and tourism behavior\{Woodside, $2004 \# 181$ \}.

Actually, Martin and Woodside already have launched a lot of relevant researches recent years. In 2007, they modeling traveler behavior by utilizing long interview method and uncovered important dimensions and relationship in travel behavior \{Martin, 2007 \#185\}. One year later, they shows a research in their book, called Tourism management: analysis, behavior and strategy, which used the long interview method to collect data from international visitors who travel to Hawaii's Big Island that demonstrated the complexity of visitors' travel decisions and behavior\{Martin, $2008 \# 182\}$.In the same place, 2011, they still based on this method constructing a gestalt modeling of international tourism behavior\{Martin, $2011 \# 186$ \}.

There are still some researches of tourism in China based on grounded theory. Corresponding to their international colleges, they also focus on the tourism behavior. Just like one of them through visited 623 negative open-ended answers, they explored the defects of the inbound tourism in China $\{$ Gao, $2010 \# 189\}$. In addition, some research ingeniously noticed on the stakeholder perceptions of tourism and illustrated the relevance of stakeholder analysis in facilitating sustainable tourism by applying the grounded theory for collecting data in the Daintree area of far north Queensland, Australia\{Hardy, 2005 \#190\}.

Despite a large part of researches based on grounded theory in tourism focused on the micro-level, just like the decision and behavior of travelers and the relationship between stakeholder perceptions and the sustainable tourism. But, there still are some studies pay attention to the macro-level. By utilized the grounded theory, Mike Weed uncover the identification of a range of tensions in the sport-tourism policy process, and the examination of the factors affecting liaison that underpin them, and finally constructed a model of the policy process for sport and tourism\{Weed, $2005 \# 184\}$.Stumpf and Swanger use the grounded 
theory method to investigate the proposed tourism policy directions of three Pacific Island countries and to develop a set of theoretical insights referred to as tourism involvement-conformance theory $\{$ Stumpf, $2015 \# 187\}$.

So, we believe the grounded theory not only be sufficient to explore the relations in the micro-level, but also be effective to constructing model in macro-level which could help as to uncover the mysterious under-economy system of tourism in ethnic minority region of southwest China.

\section{Result}

\subsection{The Two Skin Model of Yunnan Tourism Economy}

Yunnan province is located in the southwest of China, which is one of the regions in where most ethnic minorities inhabit. 25 ethnic groups live together over vast areas while some live in individual concentrated communities in small areas. Some of them inhabit in Bazi(a kind of fault basins scattered among the plateaus and mountains), just like the Bai nationality, the Hui nationality and the Naxi nationality, which already had a feudal agricultural economy before the socialist Reform of the 1950s; some of them inhabit in mountainous areas, just like Tibetans in northwest Yunnan, the Dai nationality and the Hani nationality, which were still in feudal serf society. In Tibetan regions, bkav-shag( the local government of Tibet), temple and feudal nobles constitute the Feudal Lord, who own a large number of farmland, livestock and serfs. Every year, serfs must payed the rent tax and servitude \{Yuncen, 2001 \#315\}.And the Dai implemented The Tusi System which Tusi and its retainers at all levels composed lords and the paramount leader, called Chiang Hung, owns all the land ad mountains and rivers. In this system, land be divided into almost two parts: some part of this land be regard as the 'Private Estate' of these Lords, or 'Salaries Field' of Government, which farmed by serfs without any payment; the others allocated to villages and farmed by serfs according to different status hierarchy. These serfs burdened of heavy rent, labor and a series of feudal obligations. The rest of these ethnic minorities, like the Drung nationality, the lisu nationality, the Jiangpo nationality, the Jino nationality, the Blang nationality, the Wa nationality still in primitive commune and kept the economic way of life including Public ownership of the means of production, Co-production, equally distribution $\{, \# 308\}$.

\subsection{The Contradiction Between Modern Market Economic Order and the Traditional Economic Order}

In the modern market economy, the capital as the core of its operation, it through the commodity trading which based on the use of currency to realize the capital flows and appreciation. It's economic order naturally different from the traditional economy that the self-sufficient agricultural economy based on the land and labor force. And the ethnic minorities who are directly shift from feudal serf economy or primitive commune economy to the modern market economy usually lacking the abilities of keeping the market economy well in hand. For example, a monk of a famous temple in the Naxi areas completely has no idea about money. An external businessman in local ticket agency services told us 'These years, the number of the tourists that go to this monk's temple is gradually increased, so, the income is 


\section{$\triangle$ Macrothink}

also increased correspondingly. But, this monk who manages the temple's property dose not has the ability to count the money. Every time, he booking ticket in my store, he will give me a large amount of extra money. At first, I guess he just want to test me honest operation or not, but I finally found that he exactly lacking the basic perceive about the money.' Through conversation with this businessman about the interesting monk, we notice that, this monk, may be, is not unable to recognize or count money but he definitely doesn't care about the value of this currency and has not any concept about capital accumulation. The only thing he knows is that the world is changed and he needs to use this kind of paper, called money, to buy the some daily needs of his temple. The businessman told us ' I always suggest Agee(alias of this monk) come to see me and let me help him to checking the amount when he plan to buy something, so that we can make sure he wouldn't be cheat by others. But, he always reply me wearing his unsophisticated smile said 'It doesn't matter, being happy is most important thing.' Obviously, this example looks a little extremely, but also a good spot. As we all seen, the market economy drive into this old land, and this region inevitably be modernized. The temple like Agee service for used to be the self-sufficient agricultural economy. In this kind of economy, land and labor force is not the commodity but the most essential productive forces embedded in his social life. However, at present, due to the emergence of market, they were incorporated into the into the market economy system. The income of this temple dramatically increased with the growth of tourists numbers, so that the capital is expanded unconsciously. But, the temple seems have no ideal to use the capital to improve the temples. Perhaps, concerning about the non-profit characteristic of temple, it's not appropriate to demonstrate the two skin of economy in this region. We could also to recognize the status quo of the two skin of the local economy in another perspective. In the Tibetan areas in northeast Yunnan, we could easily found that the restaurant is managed by Sichuanese, hotel is operated by Cantonese and in the Lijiang where inhabited the Naxi nationality we could also notice that, after developing the tourism, accompany with the tourists come to this region is the tourism institute like the travel agency, modernized hotel and restaurant. A young couple came from Sichuan province operating a small travel agency in this region told us 'They not good at business. They definitely lack of 'that nerve'. 'That nerve', in direct translate is a nerve which control how to deal with business. But, here, I guess, it means the ideal, spirit and the value ethics about the capitalism, just like the Max Weber said 'the protestant spirit'. The accumulation of capital needs the rationality and calculation, dedicated in their careers with all their hearts. On the contrary, the traditional agricultural economy is self-sufficient, which lacking a strong force in the pursuit of profit such as the protestants did. Moreover, in the shortage economy due to the backward productive force, they have to harmonize the potential tensions with the value ethic such as esteeming moral obligation and ignoring the interest, attaching importance to community and setting aside the individuals, respecting the morality and secondary the talent $\{\mathrm{JIn}, 2004 \# 309\}$. We all known, these ethic value above that derive from the traditional agricultural economy exactly deviate from the value orientation of market economy that pursuit the profit maximization.

And lack that kind of 'nerve', after the development of the tourism, the management and administration of the modern economic sectors base on the modern market economy are controlled only by the people with the 'protestant spirit'. The only benefit that natives could obtain is maybe a job as a guide or some meager rent from renting out their house to external 
businessman to operating a hotel of a restaurant. In other words, the wealth coming with the tourists went along the eaves flews to another wave of outsider pocket. The native ethnic minorities not only cannot benefit from this development but also crowd out from the market and occupied the local resources by external investors. As a result, the original social ecology was broken; the native ethnic minorities lost their traditionally stable social system, but the new one cannot be mastered by minorities; The outlanders who be able to operate this kind of economy, instead, crowed out the minorities from the campaign of this development; local resources be occupied by outlanders and economic resources flew out that make the life of the native ethnic minorities become more difficult.

\subsection{How to Glue the Two Skins? By Informal Tourism Economic Model}

In the circumstances above, the ethnic tensions problem should be quite complicated and sharp. The life of native ethnic minorities is broken, result in, they lost the economic foundation that they used to rely on. Furthermore, the natural resources that originally belong to them also be occupied by outsiders. While the quality of daily life be squeezed and the outsiders' income rapidly increased, it's hard to avoid ethnic tensions. How to avoid the tensions escalating? The key lies in ethnic minorities also can get rich.

Through the observation, we believe the informal economic model of Yunnan tourism is the self-repairing systems that derive from this separated social system in this circumstance. The local varieties of travel agencies, hotels and inns, restaurants and the shopping spot management by the local ethnic minority constituted an informal economic network which collected the individual travelers to form the Individual Spell Group and inducing them to spend money in these shopping spot and transportation industry.

\subsubsection{Tax Becomes the Key Method}

Usually, through the formal travel transaction would produce a lot of taxes. Firstly, when you come to the travel agency and buy a trip, it will produce a highly VAT (Value Added TAX). According to the current tax rate $17 \%\{, 2008 \# 314\}$, if the tour fee is $1000 \mathrm{RMB}$, the VAT is $170 \mathrm{RMB}$, which is directly levied by the government. That means neither the local tourism industry nor the ethnic minorities could obtain this part of profits. In addition, the VAT as the tax revenue shared by the central and local governments, the $75 \%$ of the VAT will be levied by IRS (Internal Revenue Service) that means 127.5 RMB could even not stay in the local government. (Table 2) But above all, in the formal tourism business activities, it's scarcely possible to having the item about going shopping in the local ethnic minorities' places. Even if there are still some items about shopping, it must be arrange to modern commodity trading places which definitely own the formal operation qualification. In this kind of model, the shopping spot which operated by the local ethnic minorities couldn't get any benefits. On the contrary, informal tourism economy allows tourists to buying a trip in any travel agency at a super low price. In that way, the tax is reduced to a minimum and the saving money will be spend on shopping in ethnic minorities' places. Although, these shopping spot would also distribute funds to other partners, the result is the wealth is indeed inflow into the pocket of local ethnic minorities. 
Table 2. The Comparison of these two tax flow direction

The tax flow direction in The tax flow direction in formal transaction

informal transaction

\begin{tabular}{|c|c|c|c|c|}
\hline $\begin{array}{l}\text { corporate } \\
\text { tax rate }\end{array}$ & $\begin{array}{l}\text { The central } \\
\text { government } \\
\text { levied }\end{array}$ & VAT rate & & VAT revenues \\
\hline \multirow{4}{*}{$25 \%$} & \multirow{4}{*}{$250 \mathrm{RMB}$} & \multirow{4}{*}{$17 \%$} & $\begin{array}{l}\text { The part shared by central } \\
\text { government }\end{array}$ & $\begin{array}{l}\text { The central government } \\
\text { levied }\end{array}$ \\
\hline & & & $75 \%$ & $127.5 \mathrm{RMB}$ \\
\hline & & & $\begin{array}{l}\text { The part shared by local } \\
\text { government }\end{array}$ & $\begin{array}{l}\text { The local government } \\
\text { levied }\end{array}$ \\
\hline & & & $25 \%$ & $42.5 \mathrm{RMB}$ \\
\hline
\end{tabular}

The local

government 250RMB 42.5RMB

levied

The data is compiled by the author.

\subsection{The Scramble Between Central and Local Governments}

But, what makes it confused is that how it possible for the minorities join the informal tourism economic model? The constitution of informal network usually based on the network of friends and acquaintances. Most of the varieties of travel agencies, hotels and restaurants are managed by outsiders. If there is any shopping spot in this network, it also should be hold by outsiders instead of the local ethnic minorities. To understand this abnormal phenomenon, we should go back to analysis the basic situation of this region. As we showed above, the economy operation of these areas separated into two skins, so that the ethnic tensions can't be ignored. And the only solution of relieving the tensions is help them getting rid of poverty. But, who is responsible for that? Outsiders don't care about it. The only thing they concentrated is to making money. Otherwise, the ethnic minorities themselves are unable to rein the modern market economy. Therefore, the responsibility falls on the government's shoulder. From the survey data, we can see that the government frequently appeared in this network. The Droma (the name of Tibetan girls) in Nishi Culture Village said the constitution of their village commune was conducted by government who organizing the people with skill responsible for making silverware and the people had come to the cities and speaking standard Chinese 


\section{MInstitute Macrothink $_{\text {Int }}$}

responsible for selling. Each one doses his duty and gets rid of poverty. Similarly, in Dali bai autonomous prefecture, the local guide told us the ultra-low fares are compensated by government. The largest revenue of Yunnan is come from the tobacco industry. But, the tobacco tax is national tax which is directly levied by IRS. In order to rich Yunnan, they must to developing tourism. To attract the tourists, and government subsidies the transportation costs of The Individual Spell Group. Correspondingly, the costs of travelers go to every scenic spots and shopping spots be reduced. More importantly than all of that, in every shopping spot, whatever it's located in Shangri-La or in Dali, instead of an official tax invoices, tourists could just obtain a payment receipt. Thus it can be seen, every transaction in these shopping spot escape from paying the VAT, but just pay for the quarterly corporate income tax. According to the provisions of the tax law of China, 75\% VAT return the IRS and $25 \%$ owned by local government $\{, 2016 \# 310\}$. Thence, are these entire tax invoice declare dutiable goods, $75 \%$ of the tax is equivalent to be lost. It is in this context, to constituted the commune for the local ethnic minorities to selling their featured products could not only force a large amount of wealth flew into the ethnic minority groups but also avoid the money brought by tourists, in the form of VAT, in return, levied by state. In that way, the operating income of this informal tourism network ingeniously increased, and the local tax levied by the Local Taxation Bureau correspondingly increased. What's more, in this informal economic model of tourism the wealth that brings by tourists is artfully transferred to the local ethnic minorities and the taxation should be levied by state ,nowadays, stay in the local government.

Actually, this kind of role of government is not opened, or at least is the local behavior. According to the recent annunciate that issued by National Tourism Administration of China about the Tourism industry of Yunnan province, we can find the underground features. August 8.2015, because of a tourists explored on the internet about Lijiang tour guide abuse tourists and force them shopping, National Tourism Administration paid high attention and instructed Yunnan Tourism Development Committee to launching an investigation immediately and executing strictly punishment. After the survey, Lijiang Tourism Development committee and the Shangri-La comprehensive Enforcement Bureau of Diqing Prefecture performed the administrative penalties to the involving travel agency and tour guide, and including the Nishi Culture Village which mentioned above \{Center, $2015 \# 311$ \}; February 2016, the reporters of CCTV (China Central Television) secretly investigated the tourism industry in these regions and explored their irregularities on the CCTV News such as 'Didn't invoice the tourists', 'Didn't sign a contract with tourist', 'The tour guide forced tourists shopping' and so on. In March, Yunnan Tourism Development Committee issued announcement about penalizing the involving agencies for their irregularity management behaviors like not invoice after charging trip fees, without the consent of the tourists turned them to another agency and forced tourists shopping \{Province, $2016 \# 312\}$. From these two government announcements, we can notice that the revelation of these phenomena is a top-down that all of them are disclosed firstly in the media and then the central government orders the rectifications.

Therefore, we suppose the role of local government in this kind of informal tourism economic model is not quite clear or, in other perspective, is not in totality. From Lijiang to Dali, this kind of Individual Spell Group is ubiquitous and the same as these shopping spot operated by the 


\section{MInstitute ${ }^{\text {Macrothink }}$}

local ethnic minorities, and some of them cannot be ignored in terms of their scale. It's obviously ridiculous if the governments have not ideal about these existence. And as the respondents in the surveys said all of them are the methods taken by governments to help them get rid of poverty. But, if we think the local government is one of the members of this informal economic group is definitely inaccuracy. When William F. White studied the informal economy, he believes 'their (official and informal economic organization) relationship is not on the level of totality. Officials would never achieve any kind of contracts with informal economic organizations, involving in this system is just compliance with the current social structure\{Whyte, 1943 \#229\}.' Because of the two skin economic structure of Yunnan ethnic minority regions, Yunnan has to conform to this kind of informal tourism economic model that not only channel the wealth flow into the local ethnic minorities' pockets but also guarantee the practitioners of modern tourism could also make profits in these areas.

\section{Conclusion}

The informal tourism economic model in Yunnan may be is not the unique in global tourism industry. However, there is a lot of ethnic minorities and varies in economic development. These ethnic minorities who are directly transferred from the primitive commune economy and feudal lord economy to modern market economy disable to grip the operation essence of the current economy system. What's more, the outsiders who are proficient in the market competition crowded out the natives and occupied the resources that originally belong to the local ethnic minorities. The economy of Yunnan present a two-skin pattern which one is modern market economy conducted by outsider businessman and another one is the traditional economy conducted by the local ethnic minorities.

In this circumstance, informal tourism economic model showed a kind of function to narrowing the income gap, stopping the resources flow outward and the relieving ethnic tensions. In this model, the ethnic minorities constituted commune, relying on the strength of the group to ensuring a smooth production and marketing. In addition, through reducing the tour fee in an ultra-low level to make sure the money bring in by tourist could be spent on shopping which directly channels funds to the local ethnic minorities' pocket. In this kind of informal model, changing the way of levy becomes the key method to relieving the contradiction between central and local governments. Based on this model, the VAT revenues reduced when corporate tax revenues increased that means more funds could avoid being levy by the state and stay in this region.

Become wealth, both outsiders and local minorities, by building and operating this kind of informal economic model, not only relieves the ethnic tensions and glues the two skin of Yunnan's economy but also avoid a lot of taxes levied by state and keep the funds staying in Yunnan for local use in which the variety of travel agencies, hotels and shopping spot can benefit as well as a wider range of other interest correlation groups in Yunnan. So, we believe the informal economy, actually, play an important role in some economic system especially when the modernity absent. More than that, form this research we also found that the informal economy efficiently solving the social problems, changing political force and, ultimately, effecting the people's thinking. 


\section{IIMacrothink}

\section{Funding}

This study was not funded by any institutions or programs.

\section{Ethical approval}

This article does not contain any studies with animals performed by any of the authors. And, this study got data from participants by structured interview. So, Informed consent was obtained from all individual participants.

\section{References}

Aloudat, A. S. (2014). Grounded theory, tourism. In J. Jafari \& H. Xiao (Eds.), Encyclopedia of Tourism (pp. 1-2). Cham: Springer International Publishing.

NTAIC (National tourism administration information center). (2015). About Net exposure handling of the incident, "August 24, Lijiang tour guide in the course of a dispute with visitors Development". Retrieved from http://www.cnta.com/xxfb/jdxwnew2/201508/t20150829_745936.shtml

Tourism Law of the People's Republic of China. (2015).

Feige, E. L. (1985). The Meaning of the "Underground Economy" and the Full Compliance Deficit. In W. Gaertner \& A. Wenig (Eds.), The Economics of the Shadow Economy: Proceedings of the International Conference on the Economics of the Shadow Economy, Held at the University of Bielefeld, West Germany, October 10-14, 1983 (pp. 19-36). Berlin, Heidelberg: Springer Berlin Heidelberg. https://doi.org/10.1007/978-3-642-88408-5_2

Feige, E. L. (1990). Defining and estimating underground and informal economies: The new institutional economics approach. World Development, 18(7), 989-1002. https://doi.org/10.1016/0305-750X(90)90081-8

Gao, J., Yaofeng, M. A., \& Bihu, W. U. (2010). Defects of China's Inbound Tourism from Foreign Tourists' Perspective:An Analyze Based on Grounded Theory Research Paradigm. Tourism Science.

Hardy, A. (2005). Using Grounded Theory to Explore Stakeholder Perceptions of Tourism. Journal of Tourism and Cultural Change, 3(2), 108-133. https://doi.org/10.1080/09669580508668490

Interim Regulation of the People's Republic of China on Value Added Tax (2008 Revision). (2008). The state council bulletin of the People's Republic of China, (33), 5-8.

JIn, Y. (2004). On the two-way interaction between Yunnan Minority Traditional Ethics of the Socialist Market Economic Development. (M.D), Yunnan Normal University. Available from Cnki

Martin, D. (2007). Management learning exercise and trainer's note for building grounded theory in tourism behavior. Journal of Business Research, 60(7), 742-748. https://doi.org/10.1016/j.jbusres.2007.03.002 
Martin, D., \& Woodside, A. G. (2008). GROUNDED THEORY OF INTERNATIONAL TOURISM BEHAVIOR. Journal of Travel \& Tourism Marketing, 24(4), 245-258. https://doi.org/10.1080/10548400802156695

Martin, D., \& Woodside, A. G. (2011). Gestalt modeling of international tourism behavior: Applying dimensional qualitative research in constructing grounded theory. Psychology \& Marketing, 28(10), 998-1026. https://doi.org/10.1002/mar.20425

Notice of the State Administration of Taxation on Effectively Conducting the All-out Launch of the Pilot Work of the Reform of Levying Value-added Tax in lieu of Business Tax. (2016).

PDCY (Provincial Tourism Development Committee of Yunnan). (2016). Yunnan Provincial Tourism Development Committee briefing on China Central Television reported that Dali "day trips" tourism market-related issues to be addressed. Retrieved from http://www.ynta.gov.cn/Item/25220.aspx

Stumpf, T. S., \& Swanger, N. (2015). Tourism involvement-conformance theory: a grounded theory concerning the latent consequences of sustainable tourism policy shifts. Journal of Sustainable Tourism, 23(4), 618-637. https://doi.org/10.1080/09669582.2014.959967

Weed, M. (2005). A Grounded Theory of the Policy Process for Sport and Tourism. Sport in Society, 8(2), 356-377. https://doi.org/10.1080/17430430500087815

Whyte, W. F. (1943). Street corner society : the social structure of an Italian slum: University of Chicago Press.

Woodside, A. G., MacDonald, R., \& Burford, M. (2004). Grounded Theory of Leisure Travel. Journal of Travel \& Tourism Marketing, 17(1), 7-39. https://doi.org/10.1300/J073v17n01_02

Yuncen, W. (2001). Tibet's Monastery Economy: History, Present Situations, Existing Problems vs.Countermeasures. Journal of Tibet Nationlities Institute (Philosophy and Sciences)(02), 42-49.

Yunnan Survey Yearbook of 2014.

Zi, Z. (2013). Utilization of oral archives Development of Yunnan Minority. (Ph.D), Yunnan University Available from Cnki.

\section{Copyright Disclaimer}

Copyright for this article is retained by the author(s), with first publication rights granted to the journal.

This is an open-access article distributed under the terms and conditions of the Creative Commons Attribution license (http://creativecommons.org/licenses/by/4.0/). 